\title{
High-Performance Electron Transport Layer via Ultrasonic Spray Deposition for Commercialized Perovskite Solar Cells Supporting Information
}

Jiayi Guan 1,2, Jian Ni1,2 *, Xiaojun Zhou1,2, Yue Liu1,2, Junyang Yin 1,2, Jinlin

Wang 1,2, Dan Wang1,2, Yaofang Zhang3, Juan Li1,2, Hongkun Cai1,2, Jianjun

\section{Zhangl,2}

1.Department of Electronic Science and Technology, College of Electronic Information and Optical Engineering, Nankai University, Tianjin 300350, China

2. Key Laboratory of Photoelectronic Thin Film Devices and Technology of Tianjin, Tianjin 300350, China

3. School of Physical Science and Technology, Tiangong University, Tianjin 300387, China

*Email: nijian_nankai@163.com
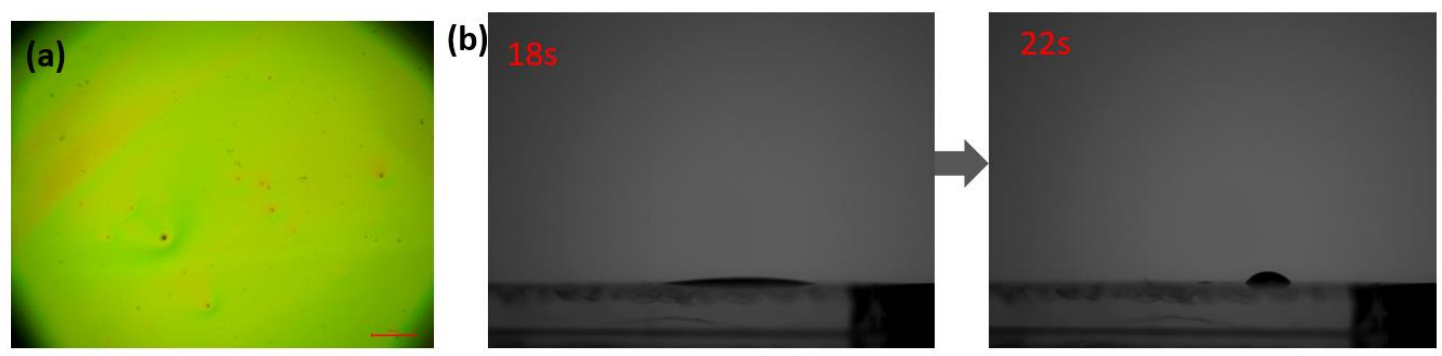

Figure S1. (a)The microscope test of the tailing phenomenon when the substrate temperature was $40^{\circ} \mathrm{C}$. The scale is $100 \mu \mathrm{m}$. (b)The pictures of droplet when the drying time was from $18 \mathrm{~s}$ to $22 \mathrm{~s}$ in this case the substrate temperature was $100^{\circ} \mathrm{C}$. The ratio of the width to the height decreased sharply in the later stage of drying. 


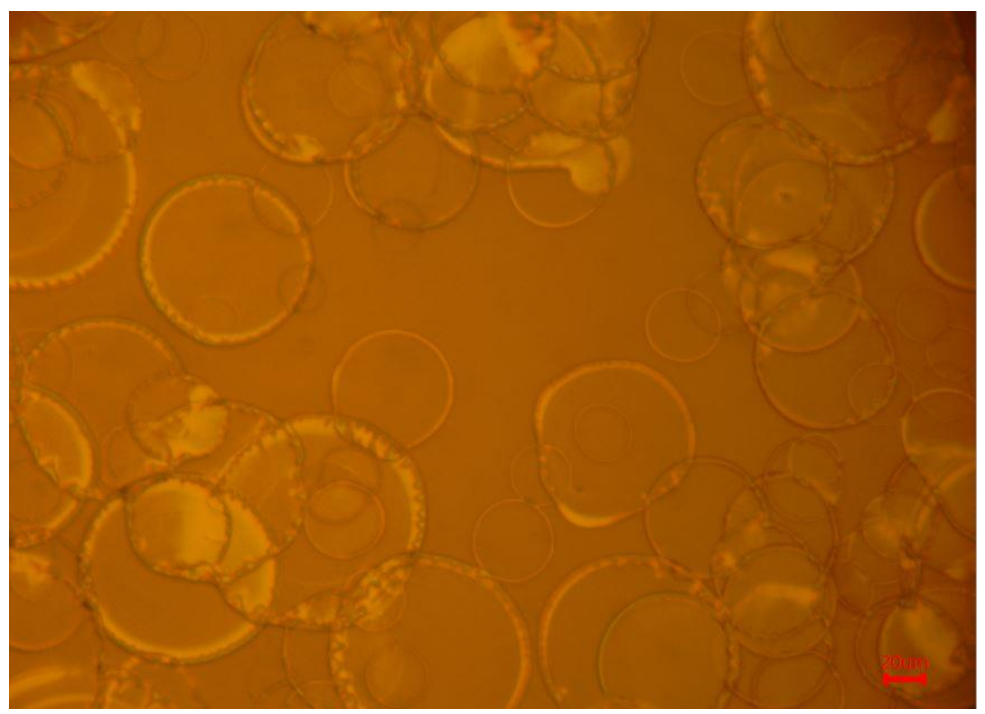

Figure S2. The optical image of 'coffee ring' when the substrate temperature was $150^{\circ} \mathrm{C}$.

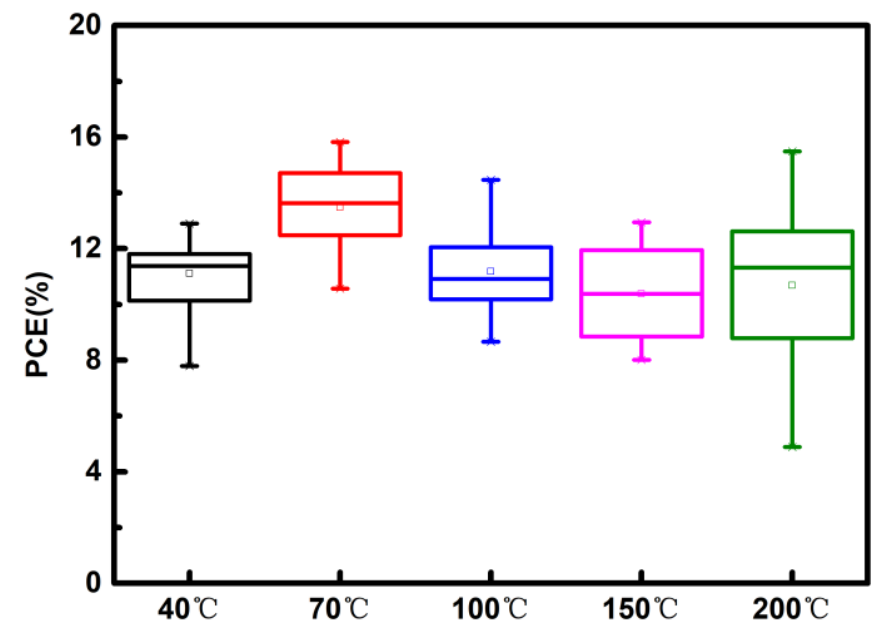

Figure S3. The J-V box plot of different PSCs based on $\mathrm{SnO}_{2}$ ETLs with different substrate temperatures.

Table S1. The series resistance and parallel resistance calculated with the J-V curves of PSCs based on different concentration $\mathrm{SnO}_{2}$ precursors.

\begin{tabular}{|c|c|c|}
\hline Concentration $(\mathrm{mg} / \mathrm{ml})$ & Series resistance $(\Omega)$ & Parallel resistance $(\Omega)$ \\
\hline 5 & 100.764 & 9786.651 \\
\hline 15 & 74.850 & 8235.875 \\
\hline 28 & 49.569 & 5405.698 \\
\hline 43 & 50.626 & 3070.782 \\
\hline
\end{tabular}


Table S2. The specific value of Rct that fitted by EIS tests.

\begin{tabular}{|c|c|}
\hline Concentration(mg/ml) & $\operatorname{Rct}(\Omega)$ \\
\hline $5 \mathrm{mg} / \mathrm{ml}$ & 13.41 \\
\hline $15 \mathrm{mg} / \mathrm{ml}$ & 8.14 \\
\hline $28 \mathrm{mg} / \mathrm{ml}$ & 6.46 \\
\hline $43 \mathrm{mg} / \mathrm{ml}$ & 8.2 \\
\hline
\end{tabular}
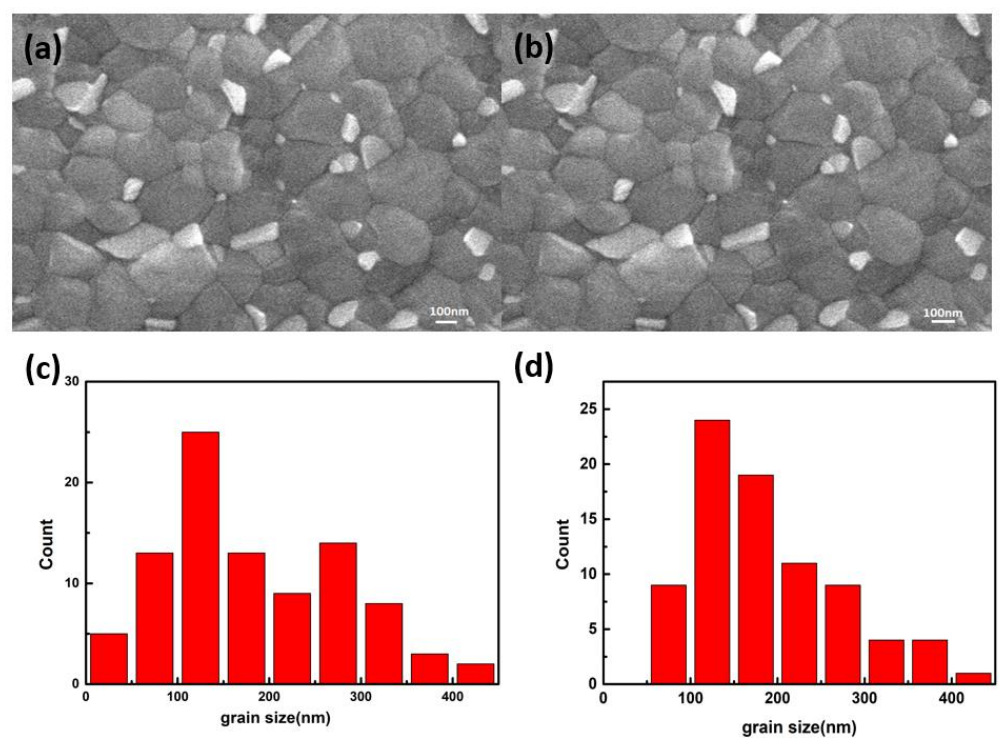

Figure S4. (a, b) SEM images of the perovskite layer deposited on the $\mathrm{spi}^{-\mathrm{SnO}_{2}}$ and the $\mathrm{spr}_{-} \mathrm{SnO}_{2}$. (c,d) The corresponding frequency distribution histogram of the perovskite grain.

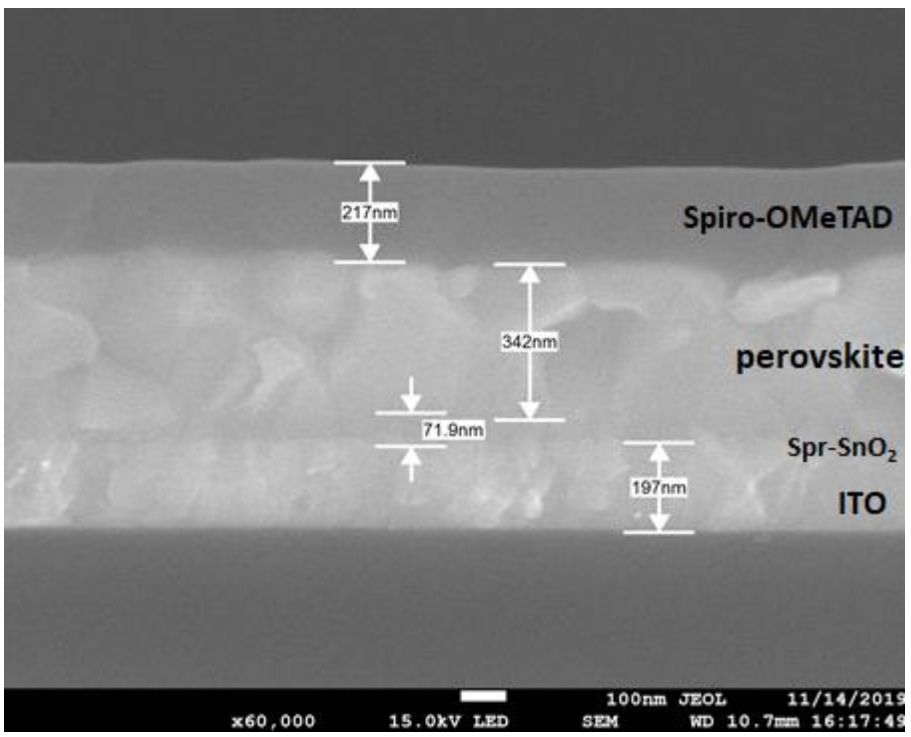

Figure S5. Cross-sectional SEM image of the PSC device based on the $\mathrm{spr}_{-} \mathrm{SnO}_{2}$. 


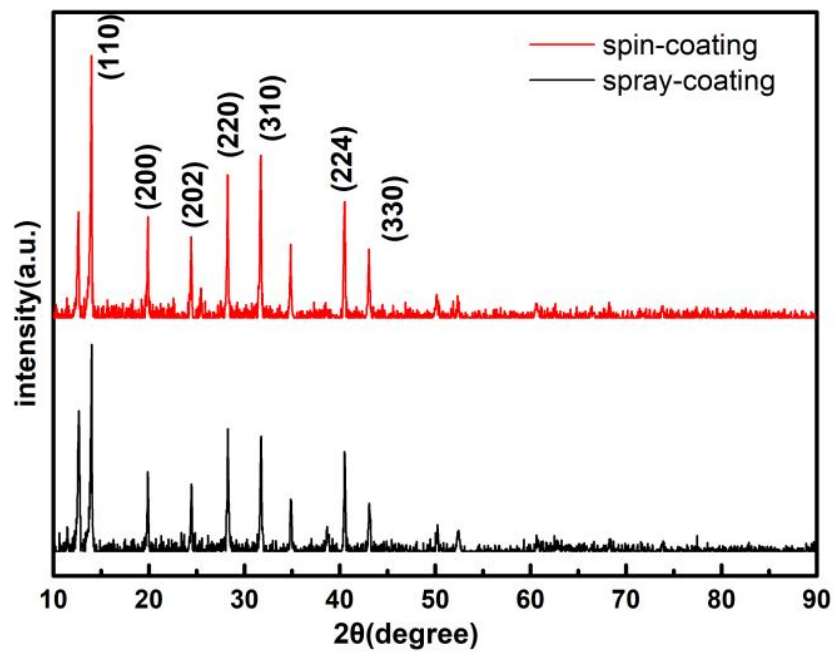

Figure S6. XRD pattern of the perovskite deposited on the spi- $\mathrm{SnO}_{2}$ and the $\mathrm{spr}-\mathrm{SnO}_{2}$.

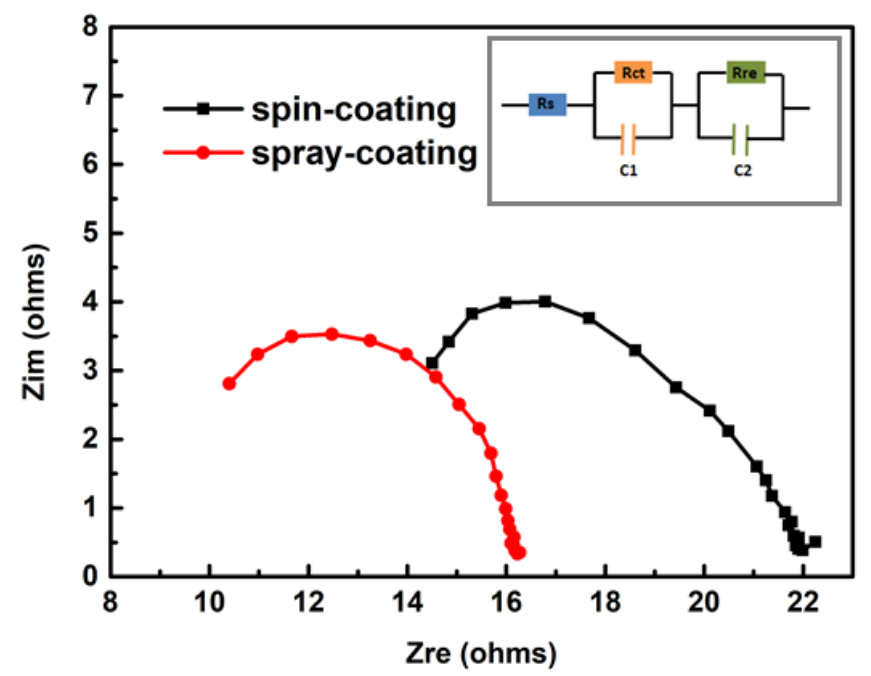

Figure S7. EIS diagram of the PSCs based on the spi- $\mathrm{SnO}_{2}$ and the $\mathrm{spr}-\mathrm{SnO}_{2}$. The illustration is the equivalent circuit diagram. 


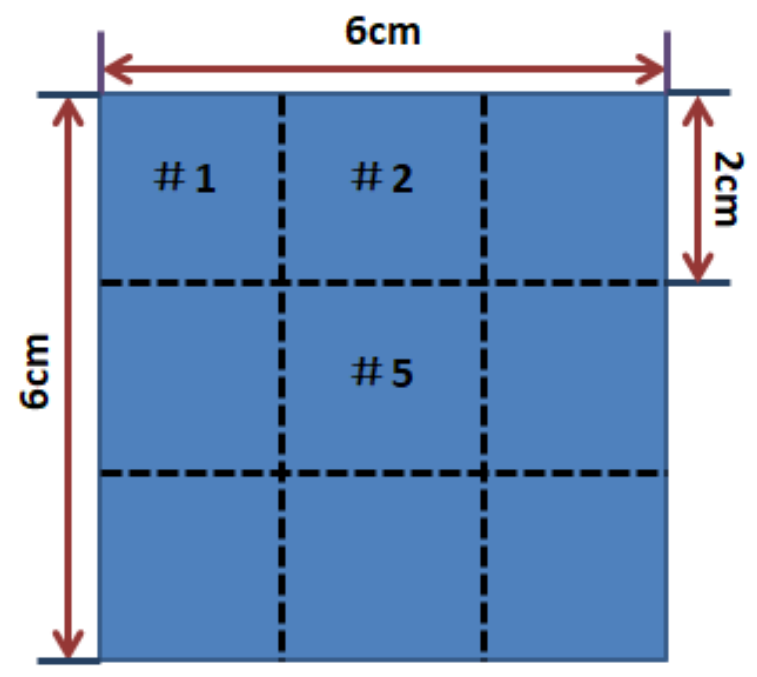

Figure S8. Diagram of $6 \mathrm{~cm} * 6 \mathrm{~cm}$ large-area PSC. 